\title{
International Telecommunication Union Standardization for Trust Provisioning in Information, Communication and Technology Infrastructure toward Achieving United Nation's Sustainable Development Goals
}

\author{
Maryam Roshanaei, Qiang Duan \\ Information, Science and Technology Department, The Pennsylvania State University, Abington College, Abington, PA, USA \\ Email: Mur45@psu.edu, QDuan@psu.edu
}

How to cite this paper: Roshanaei, M. and Duan, Q. (2021) International Telecommunication Union Standardization for Trust Provisioning in Information, Communication and Technology Infrastructure toward Achieving United Nation's Sustainable Development Goal. Journal of Computer and Communications, 9, 44-59.

https://doi.org/10.4236/jcc.2021.910004

Received: August 10, 2021

Accepted: October 10, 2021

Published: October 13, 2021

Copyright $\odot 2021$ by author(s) and Scientific Research Publishing Inc. This work is licensed under the Creative Commons Attribution International License (CC BY 4.0).

http://creativecommons.org/licenses/by/4.0/

\section{(c) (i) Open Access}

\begin{abstract}
The advancement of the fourth industrial revolution has shaped the integration and interaction of different information, communication and technologies (ICTs) in the merging cyber, physical, and social infrastructures. The impact of ICT has accelerated the progress of the United Nation's Sustainable Development Goals (UN SDGs) and influenced the evolution of smart, sustainable, stable society development. Making the trustworthy information and communication technologies infrastructure widely available will promote the community innovation needed to stimulate domestic economics, provide decent work, and reduce inequalities. This article attempts to outline a big picture about the International Telecommunication Union (ITU)'s trust provisioning framework, including its motivation, current status, and application for achieving the UN SDGs by 2030. This article first describes the purpose of the UN SDGs and the evolution of the industrial revolution, then demonstrates the challenges of global risks affecting the fourth industrial revolution and the need for trustworthy ICT infrastructures. Subsequently, the article evaluates the ITU trust provisioning framework and assesses its applications in the future knowledge society, trust provisioning ecosystem, and cyber, physical, and social infrastructure toward achieving UN SDGs. Use cases are also presented in this article to show the effectiveness of the ITU trust provisioning framework on achieving UN SDGs.
\end{abstract}

\section{Keywords}

Trust Provisioning, Fourth Industrial Revolution, Information, 
Communication and Technologies, Sustainable Development Goals, Global

Risks, Cyber, Physical and Social Infrastructure

\section{Introduction}

In 2015, the UN recognized seventeen Sustainable Development Goals (SDGs) to be achieved by 2030 ranging from eradicating poverty, guaranteeing stability, and peace to fight discrimination and climate change. It is recognized by the UN that eradicating poverty and hunger must go conjointly with strategies to improve healthy lives and promote well-being for all ages. Moreover, it plans to achieve quality education and gender equality for all while ensuring access to clean water and sanitation; affordable, reliable, sustainable, and modern energy. The goals continue promoting inclusive and sustainable economic growth, employment, and decent work for all. The strategies are to accelerate building resilient infrastructure, promote sustainable industrialization, and foster innovation while ensuring to take urgent action to combat climate change and its impacts. Ultimately, it is to promote just, peaceful and inclusive societies; revitalize the global partnership for sustainable development. The United Nations' 17 sustainable development goals (SDGs) are shown in Table 1.

The SDGs were created on decades of work by different countries and the UN. As shown in the UN SGDS timeline in Figure 1, in 1992, Agenda 21 adopted a comprehensive plan of action to build a global partnership for sustainable development to improve human lives and precede environment. By 2000, the UN launched the eight Millennium Development Declaration Goals (MDGs) to reduce extreme poverty. Following on, in 2002 the Johannesburg declaration was a commitment to end poverty by building on Agenda 21 and the Millennium declaration. In 2012, the UN conference on sustainable development launched "The future we want". At this conference, it is decided to develop a set of SDGs to

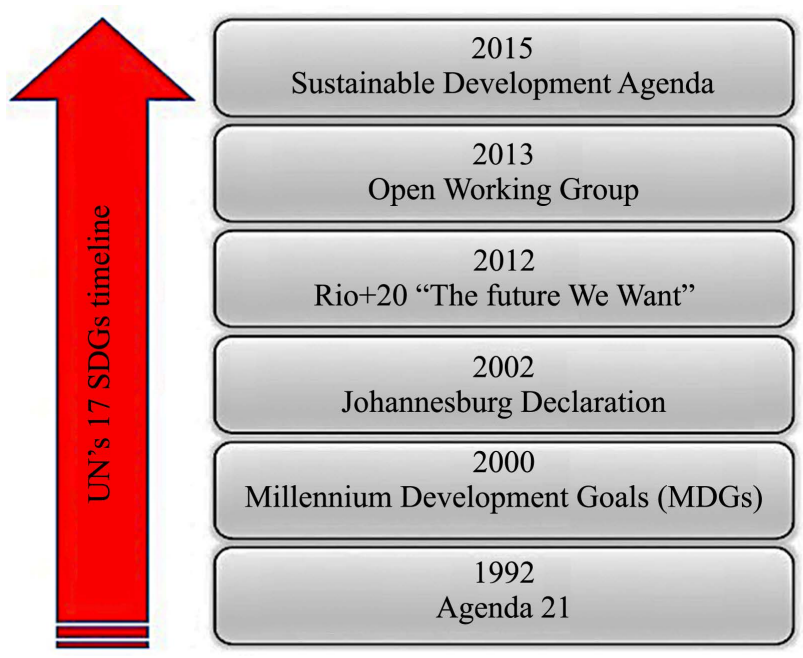

Figure 1. UN's SDGs timeline. 
Table 1. United Nations (UN)'s 17 Sustainable Development Goals (SDGs).

\begin{tabular}{|c|c|c|}
\hline Goals & UN SDGs & Description \\
\hline Goal 1 & No Poverty & End poverty in all its forms everywhere \\
\hline Goal 2 & Zero Hunger & $\begin{array}{l}\text { End hunger, achieve food security and improved nutrition } \\
\text { and promote sustainable agriculture }\end{array}$ \\
\hline Goal 3 & $\begin{array}{l}\text { Good Health \& } \\
\text { Well-Being }\end{array}$ & $\begin{array}{l}\text { Ensure healthy lives and promote well-being for all at all } \\
\text { ages }\end{array}$ \\
\hline Goal 4 & $\begin{array}{l}\text { Quality } \\
\text { Education }\end{array}$ & $\begin{array}{l}\text { Ensure inclusive and equitable quality education and } \\
\text { promote lifelong learning opportunities for all }\end{array}$ \\
\hline Goal 5 & Gender Equality & Achieve gender equality and empower all women and girls \\
\hline Goal 6 & $\begin{array}{l}\text { Clean Water } \\
\& \text { Sanitation }\end{array}$ & $\begin{array}{l}\text { Ensure availability and sustainable management of water } \\
\text { and sanitation for all }\end{array}$ \\
\hline Goal 7 & $\begin{array}{l}\text { Affordable \& } \\
\text { Clean Energy }\end{array}$ & $\begin{array}{l}\text { Ensure access to affordable, reliable, sustainable and } \\
\text { modern energy for all }\end{array}$ \\
\hline Goal 8 & $\begin{array}{l}\text { Decent Work \& } \\
\text { Economic Growth }\end{array}$ & $\begin{array}{l}\text { Promote sustained, inclusive and sustainable economic } \\
\text { growth, full and productive employment and decent work } \\
\text { for all }\end{array}$ \\
\hline Goal 9 & $\begin{array}{l}\text { Industry, Innovation } \\
\quad \& \text { Infrastructure }\end{array}$ & $\begin{array}{l}\text { Build resilient infrastructure, promote inclusive and } \\
\text { sustainable industrialization and foster innovation }\end{array}$ \\
\hline Goal 10 & Reduce Inequalities & Reduce inequality within and among countries \\
\hline Goal 11 & $\begin{array}{l}\text { Sustainable Cities } \\
\text { \& Communities }\end{array}$ & $\begin{array}{l}\text { Make cities and human settlements inclusive, safe, } \\
\text { resilient and sustainable }\end{array}$ \\
\hline Goal 12 & $\begin{array}{l}\text { Responsible } \\
\text { Consumption \& } \\
\text { Productions }\end{array}$ & Ensure sustainable consumption and production patterns \\
\hline Goal 13 & Climate Action & $\begin{array}{l}\text { Take urgent action to combat climate change and its } \\
\text { impacts }\end{array}$ \\
\hline Goal 14 & Life Below Water & $\begin{array}{l}\text { Conserve and sustainably use the oceans, seas and marine } \\
\text { resources for sustainable development }\end{array}$ \\
\hline Goal 15 & Life on Land & $\begin{array}{l}\text { Protect, restore and promote sustainable use of terrestrial } \\
\text { ecosystems, sustainably manage forests, combat } \\
\text { desertification, and halt and reverse land degradation and } \\
\text { halt biodiversity loss }\end{array}$ \\
\hline Goal 16 & $\begin{array}{l}\text { Peace, Justice \& } \\
\text { Strong Institution }\end{array}$ & $\begin{array}{l}\text { Promote peaceful and inclusive societies for sustainable } \\
\text { development, provide access to justice for all and build } \\
\text { effective, accountable and inclusive institutions at all levels }\end{array}$ \\
\hline Goal 17 & $\begin{array}{l}\text { Partnerships } \\
\text { for the Goals }\end{array}$ & $\begin{array}{l}\text { Strengthen the means of implementation and revitalize the } \\
\text { global partnership for sustainable development }\end{array}$ \\
\hline
\end{tabular}

build upon the MDGs. In 2013, the General Assembly established an Open Working Group for developing a proposal on the SDGs. After two years, in 2015, the General Assembly launched the negotiation process on the post-2015 development agenda and finally adopted the 2030 Agenda for Sustainable Development, with seventeen SDGs ${ }^{1}$ at its core. Today, the Sustainable Develop${ }^{1} \mathrm{UN} 2030$ agenda for sustainable development available: https://sdgs.un.org/goals. 
ment forum serves as the central UN platform for accelerating and assessing the SDGs.

Effect of the fourth industrial revolution in achieving SDGs goals

Nevertheless, achieving SDGs goals creates a significant gap between where the SDGs goals are and how they could be sufficiently delivered. The significate contributions of emerging technology can play a major role in bridging this gap. World Economic Forum ${ }^{2}$ first introduced the idea of the fourth industrial revolution (4IR) in 2016 which is significantly different from the ones preceding it. The first industrial revolution was triggered by water and steam power to mechanize production, the second industrial revolution used electric power to produce mass production and the third used electronics and information technology to automate production. The 4IR represents mass digitization creating essential change in the manner communities live, work, connect, and share. Compared to past industrial revolutions, the 4IR is evolving at an exponential rather than a linear pace. It is transforming human development that is empowered by innovation advancements in the first, second, and third industrial revolution. Consequently, the merging cyber, physical, and social infrastructures to enhance sustainability and stability of the communities' standards. Mass digitization is the core of 4IR where innovative Information and Communication Technologies (ICTs) are applied to tackle the technical and socio-economic challenges. ICT can be referred to as a diverse set of technological tools and resources used to create, store, transmit, share, or exchange information. The rapid growth of the 4IR is forcing the nations to reconsider in what way they should grow, in what manner establishments could contribute, and exactly how to implement it all together to the new standards [1]. These frontier technological tools and resources include but are not limited to artificial intelligence, machine learning, precision medicine, autonomous vehicles, and drones. United nation (UN) has defined an ICT strategy roadmap [2] to support developments in areas of peace and security, human rights, international law, humanitarian affairs, and most importantly sustainable development. The strategy was designed based on five pillars: 1) Modernize to support strategic priorities on technology advancement, 2) Transform to restructure ICT globally for services enhancement, 3) Innovate to foster innovative solution, 4) Optimize to support ICT resources for business objective and 5) Govern to strengthen governance and accountability. Figure 2 summarizes the industrial revolution timeline. The acceleration and scale 4IR mass digitalization enables unparalleled interactions between society, physical infrastructure, and cyberspace. Consequently, the importance of their interaction creates a relationship between knowledge society, information society, and trust for substantial progression toward UN' SDGs achievement. Sustainable development requires the transformation of societies into knowledge societies with individual knowledge assets formed by the information society. The information society disseminates the raw data into meaningful information transferring into resources that allow society to take effective action. Consequently,

${ }^{2}$ World Economic Forum Available: https://www.weforum.org/. 


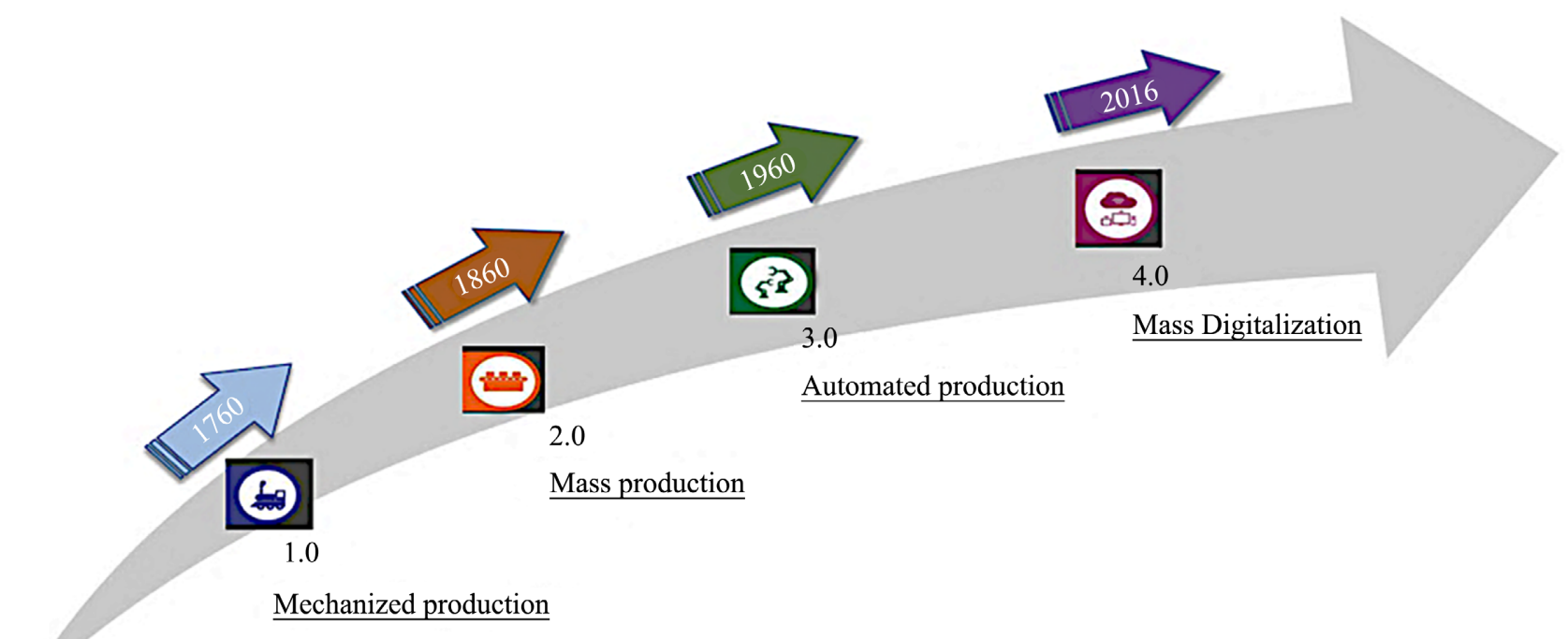

Figure 2. Industrial revolution timeline.

these actions create measurable trust provisioning and assurance between knowledge and information society [3]. While the enormous potential 4IR solutions provide a positive contribution to SDGs goals, the barriers and global risks must be addressed to provide a trustworthy society, physical infrastructure, and cyberspace. The ITU and global digital report estimated that more than $50 \%$ of the world's population is now online ${ }^{3}$ and approximately one million people go online for their first time each day ${ }^{4}$. According to Cisco's annual Internet report [4], there will be 29.3 billion network services by 2023, up from 18.4 billion in 2018. The 4IR technologies bring enormous global economic opportunities and societal benefits. They are noticeably reshaping economics and societies through technology innovations such as using quantum computing, precision medicine, autonomous vehicles, drones, and artificial intelligence. The fast-growing 4IR technologies are expected to boost global growth by $14 \%$ by 2030 . Although the fast-growing digital innovation is bringing tremendous benefits to the global economy, the lack of cyber insecurity, trustworthiness, and global technology governance framework escalates the global risk of fragmented cyberspace and competing technology regulation. The nature of these technologies makes them substantially vulnerable and untrustworthy. The Global risks report $2020^{5}$ recognized cyber attacks among the top five risks along with extreme weather, climate action failure, natural disasters, and biodiversity loss risks. The cyber attacks risk can cause significant harmful impacts and adverse consequences on technological advances, critical information infrastructure, and massive exploi-

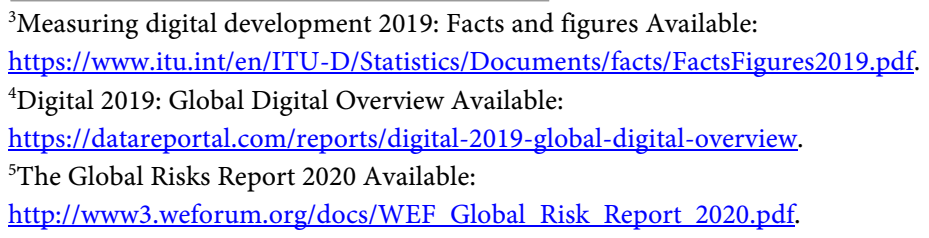


tation of data on an unprecedented scale. The 4IR exponential speed in mass digitalization makes trust provisioning a major challenge in providing confidentiality, integrity, and availability of data. As a result, the need for measurable confidence and protection plays an essential key role in building a trust provisioning ecosystem in information and communication technologies and their infrastructure. Building a trust provisioning ecosystem allows cyber, physical, and social entities to predict the outcomes of their integration and interaction and minimizes their risks. ITU is the UN specialized agency for ICTs development. ITU's strategy in achieving UN SDGs is to leverage the power of trustworthy ICTs in allocating technical standards, ensuring information and technologies interconnection, and improving access to ICTs to all developed and developing communities worldwide. ITU's approach is using ICTs advancement in 4IR mass digitalization to accelerate progress towards every single one of the 17 UN SDGs. The ITU's key role in SDG achievement is to build trusted and resilient cyber-physical-social (CPS) infrastructure and promote comprehensive sustainable development through advancing innovations.

\section{Trust Provisioning in Information and Communication Technology Infrastructure}

\section{Trust in Cyber, Physical and Social Infrastructures}

Recognizing the trust provision in ICT begins with evaluating the term trust. Generally, trust has no universally accepted definition. Nevertheless, numerous establishments such as governments, academia, industry, and others have attempted to conceptualize the term trust as a multi-layered variable with three distinct but interrelated dimensions 1) propensity to trust (trustor) 2) perceived trustworthiness (trustee) 3) provisioning and monitoring frameworks. Furthermore, in cyberspace, trust is described as a fundamental concept in cybersecurity and cyber privacy where the term trust in the technological aspects and user aspects are essential. It utilizes directly both cybersecurity and cyber privacy mechanisms, therefore, assuring the trustworthiness of the services for the users. The implementation of trust provisioning framework begins in recognizing the emerging knowledge and information societies that encompass all human activities in a cyber, physical and social infrastructure (CPS). The CPS infrastructure shown in Figure 3, contains three main entities [5]: 1) Cyber entities provides an interdependent network of information technology infrastructures and platform either on-premise or in the Cloud, 2) Physical entities consists of any physical devices such as sensors, actuators, getaways and the underlying infrastructures, 3) Social entities contains human-based interaction and their interconnected devices/agents, and/or social platforms. The trust in ICTs [6], especially on trust provisioning, is closely associated to but different from the concepts of cyber security and privacy. While cybersecurity primarily concerns technical aspects of the infrastructure such as system confidentiality, availability and integrity, cyber privacy mainly emphasizes on user characteristics to support anonymity and 


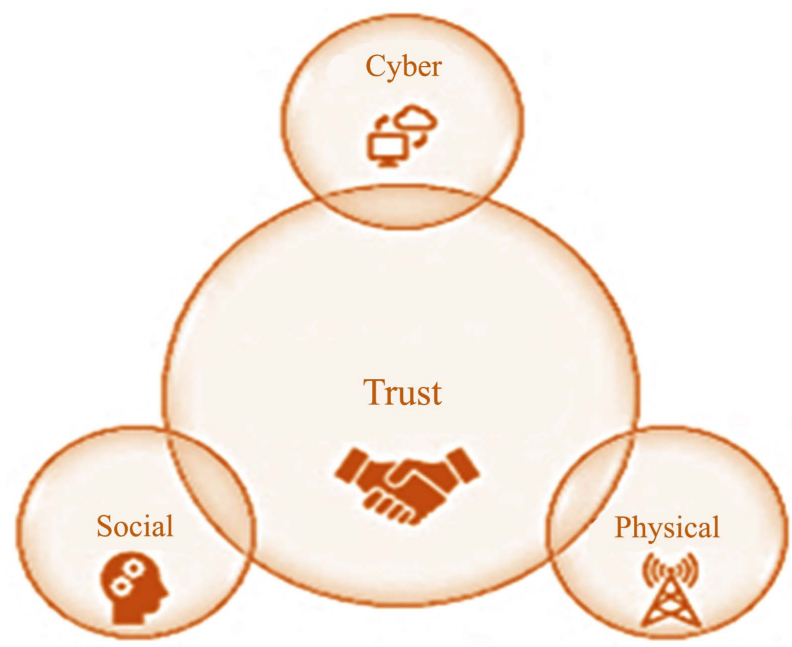

Figure 3. Trust in cyber-physical-social (CPS) infrastructure.

restrictive handling of personal user data. Trust provisioning ecosystem comprises both aspects of cybersecurity and cyberprivacy. It revolves around building confidence from physical, cyber, and social functions and their performances that can be used for producing chains of activities in ICT services and infrastructure. Trust utilizes both cybersecurity and privacy mechanisms to assure the trustworthiness of services for the users.

\section{ITU Trust Measurement and Provision Ecosystem}

ITU's study of trust in ICTs [7] has focused on trust provisioning and standardization to support the 4IR emerging technologies advancement in ICT. The ITU's recommendations [8] and [9] convened the trust measurement to be evaluated with quantitative or qualitative cyber, social and physical values. A trustor and a trustee create an association based on their attributes. The attribute of trust propensity's trustor is a typical expectation about the trustee's trustworthiness. Consequently, the attribute of trustworthiness of the trustee indicates an entity that can provide reliability and trust for the trustor. A trustor attribute assesses three types of information for the trustworthiness of trustee 1) awareness of trustor about the trustee, 2) trustor's knowledge gain through the trustee interaction and 3) the measure of trustee's trustworthiness. The trustworthiness attributes can be described as measured trusted information available to the trustor.

The ITU recognized the study of trust in ICTs as a direct trust measurement attributes into three main entities 1) Capability entity facilitates the influence of attributes such as robustness, safety, stability, scalability, and reliability, 2) Integrity entity promote the trustworthiness of social, cyber and physical domains by implementing attributes such as completeness, consistency, accuracy, certainty, and recency and 3) Cooperation entity leverage the trust of trustee and trustor by enforcing attributes such as availability, assurance, relevance, and credibility. While direct trust attributes leverage the trust measurement, a trustor may additionally measure the trustworthiness of a trustee implicitly using the knowledge 
gain through prior interaction with the trustee and trustworthiness gained through inclusive views of the trustee. Measurement of these three categories of direct trust attributes in the cyber, physical, and social domains is shown in Table 2.

The ITU Trust Measurement creates a trusted ecosystem in advancing toward a knowledge society that requires trust to obtain reliable information from raw data. While physical entities are provisioning intelligent services, decisions, and executions without social intervention, trust has also been emphasized as an important fundamental in data handling and service provisioning. The computation, communication, and control (3Cs) are defined as the main elements of CPS infrastructures to obtain knowledge from the information gathered in the raw data provided by physical entities [10]. Furthermore, trust is an essential factor in acquiring knowledge. Consequently, the DIKW (data, information, knowledge, and wisdom) process can directly correlate with CPS infrastructure functionality to create a trusted environment as shown in Figure 4.

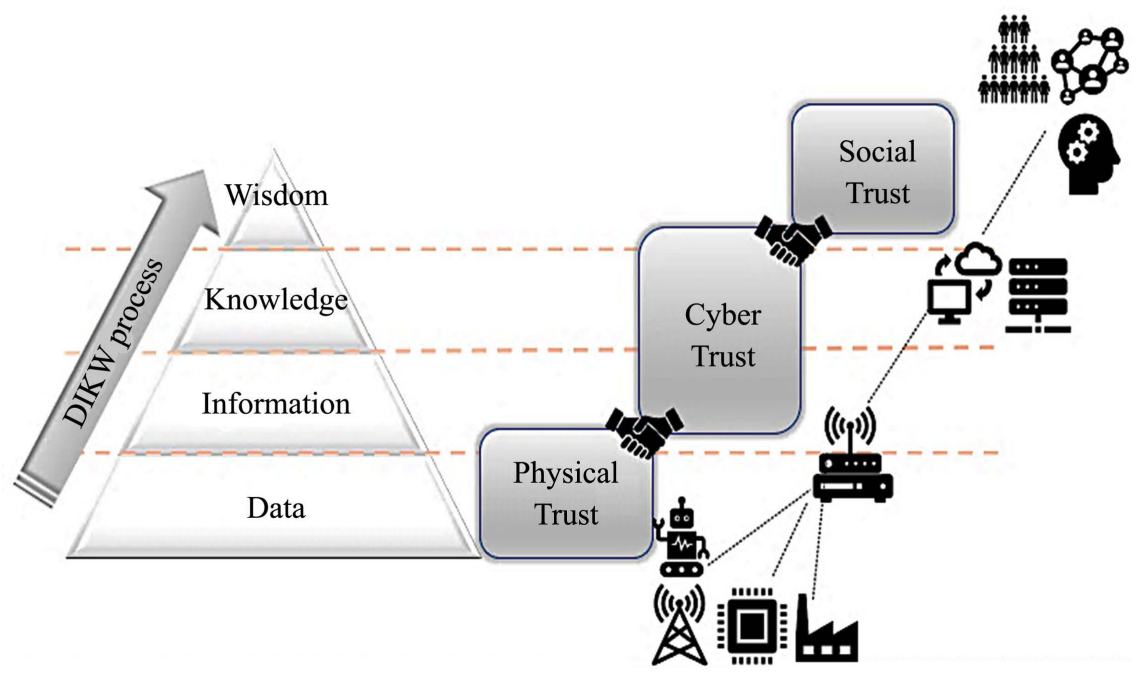

Figure 4. Trust provisioning ecosystem.

Table 2. Attributes for trust measurement.

\begin{tabular}{clll}
\hline \multicolumn{1}{c}{$\begin{array}{c}\text { Trust } \\
\text { Measurement }\end{array}$} & \multicolumn{1}{c}{ Capability } & \multicolumn{1}{c}{ Integrity } & \multicolumn{1}{c}{ Cooperation } \\
\hline \multirow{2}{*}{ Cyber Trust } & $\begin{array}{l}\text { Facilitate Cyber } \\
\text { entities to execute, } \\
\text { control, process and } \\
\text { communicate }\end{array}$ & $\begin{array}{l}\text { Promote cyber entities to } \\
\text { handle data and not altered } \\
\text { during control, process and } \\
\text { communication }\end{array}$ & $\begin{array}{l}\text { Leverage cyber entities } \\
\text { work together for their } \\
\text { common purposes }\end{array}$ \\
Physical Trust & $\begin{array}{l}\text { Facilitate of the } \\
\text { physical entities to } \\
\text { perform its task with } \\
\text { correct functionality }\end{array}$ & $\begin{array}{l}\text { Promote physical } \\
\text { entities to be stable without } \\
\text { trouble or breakdown }\end{array}$ & $\begin{array}{l}\text { Leverage Physical entities } \\
\text { work together for their } \\
\text { common purposes }\end{array}$ \\
Social Trust & $\begin{array}{l}\text { Facilitate social } \\
\text { capabilities in the } \\
\text { individual's activity }\end{array}$ & $\begin{array}{l}\text { Promote trustworthiness } \\
\text { in the sociality }\end{array}$ & $\begin{array}{l}\text { Leverage Social entities } \\
\text { work together for their } \\
\text { common purposes }\end{array}$ \\
\hline
\end{tabular}




\section{ITU Standardization for Trust Provisioning in ICT Infrastructures}

ITU started groundbreaking work on future trusted ICT infrastructures and services in 2015 through the establishment of the Corresponding Group on Trust (CG-Trust) in Study Group 13 (SG-13). The CG-Trust group first completed a technical report on trust provisioning for future ICT infrastructures and services in 2016 [11]. Then it conducted research on trust provisioning and developed a series of recommendations in a four-year study cycle from 2017 to 2020.

\section{ITU's Trust Provisioning Framework}

As shown in Figure 5, the ITU trust provisioning framework [9] is made of four substantial building blocks: 1) Trust Agent obtains knowledge from trusted raw data in CPS environment. 2) Trust Analysis and management Platform examines whether the object satisfies certain trust criteria. 3) Trust service enabler identifies the trust knowledge objects based on CPS infrastructure and provides trust-adapting for backward capabilities adaptation to legacy or new services and 4) Trust service broker provides a broker service.

Table 3 shows the ITU trust provision framework building blocks including the function modules of each block and their descriptions.

\section{Trust Evaluation for ITU's Trust Provisioning Framework}

The trust evaluation is outlined [9] as a way of assessing, measuring and, quantifying trust for target services or objects to associate the level of trust between different entities. The trust evaluation required three types of trust information 1) Trust attributes provide information of an entity that associates trust directly or indirectly to qualitative, assessable, and measurable types, 2) Trust indicators provide information of an entity that associates trust objectively and
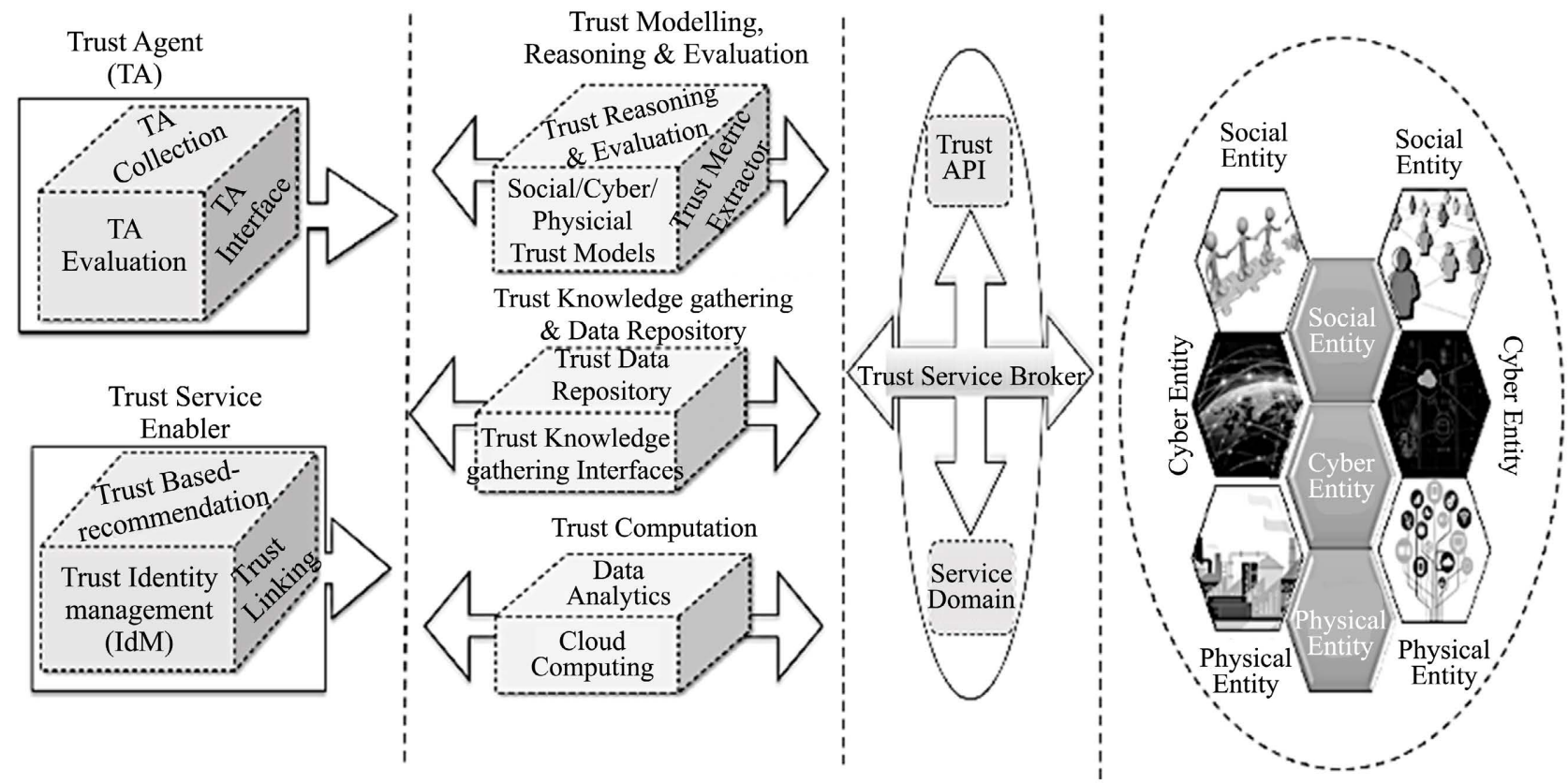

Figure 5. ITU trust provisioning framework. 
Table 3. Building blocks of ITU's trust provisioning framework.

\begin{tabular}{|c|c|}
\hline \multicolumn{2}{|r|}{ Trust Agent } \\
\hline Modules & Description \\
\hline Interface & $\begin{array}{l}\text { TA creates insubstantial interfaces to process the knowledge } \\
\text { gained from trusted raw data extracted from physical entities. } \\
\text { Moreover, the interfaces have a capability connecting to } \\
\text { physical entities platforms }\end{array}$ \\
\hline Collection & $\begin{array}{l}\text { Trusted data collation is to evaluate the trust level, identify the } \\
\text { required trust metrics object, and generate awareness for the trust } \\
\text { analysis and management platform }\end{array}$ \\
\hline Evaluation & Trusted data is to filter and refine the trust data for trust evaluation \\
\hline \multicolumn{2}{|c|}{ Trust Analysis and Management Platform (TAMP) } \\
\hline Modules & Descriptions \\
\hline Trust Modelling & Creates trust relationships between entities for analyzing trust data \\
\hline $\begin{array}{l}\text { Trust Reasoning } \\
\text { and Evaluation }\end{array}$ & Analyze and assess trust level based on the trust Modelling \\
\hline Trust Metric Extractor & $\begin{array}{l}\text { 1) Creates trust modeling metrics } 2 \text { ) Identify trust characteristics } \\
\text { 3) report the factors influencing trust }\end{array}$ \\
\hline \multicolumn{2}{|r|}{ Trust Service Enabler } \\
\hline Modules & Description \\
\hline Trust linking & Links the objects based on trust criteria \\
\hline $\begin{array}{l}\text { Trust identity } \\
\text { management (IdM) }\end{array}$ & $\begin{array}{l}\text { Digital identification/authentication of objects management, } \\
\text { ensuring the trustworthy objects identification } \\
\text { and supporting trust-based services and applications. }\end{array}$ \\
\hline $\begin{array}{c}\text { Trust } \\
\text { Based-recommendation }\end{array}$ & $\begin{array}{l}\text { Provides recommendation for selecting an appropriate } \\
\text { objects that meet the trust level }\end{array}$ \\
\hline \multicolumn{2}{|r|}{ Trust Service Broke } \\
\hline Modules & Description \\
\hline $\begin{array}{l}\text { Domain-specific } \\
\text { trust knowledge }\end{array}$ & $\begin{array}{l}\text { Disseminate domain-specific trust knowledge across service } \\
\text { domains via other TAMPs, }\end{array}$ \\
\hline Trust knowledge & $\begin{array}{l}\text { Create knowledge between trust governance information and } \\
\text { trust application programming interface (API) }\end{array}$ \\
\hline
\end{tabular}

subjectively to emphasize trustworthiness and individuality, 3) Trust index provides information of an entity that associates multiple trust indicators into one standard to quantify the trustworthiness.

\section{ITU's Trust Provisioning Developments}

Trust provisioning in ICT infrastructures and services contains of a set of processes that contain collecting data from entities, generating and disseminating trust information by assessing all features of trust to support the decision-making of entities when creating trust relationships with other entities.

Typical processes for trust provisioning include 1) data gathering; 2) data 
managing; 3) trust information analysis; 4) dissemination of trust information; and 5) trust information lifecycle management. The data collection process gathers raw data on trust information. This process determines the types and amount of data that should be collected based on the purpose of trust provisioning. The data management process uses the collected data to generate trust information. The meaningful trust information will be extracted from data for the trust information analysis. A trust model is used in this process to obtain trust information to fully comprehend trust attributes and justify trust factors. Then the analyzed trust information, including the obtained trust index, is distributed in the process of dissemination. Due to the dynamic trust characteristics, the trust information lifecycle manages the trust information to be generated, reorganized, and destroyed.

\section{Application of ITU Trust Provisioning Framework in Communication Systems}

A use case for applying the ITU trust provisioning framework [9] for intermediate device selection in a device-to-device communication environment is shown in Figure 6. This use case is an example of a generic conceptual model that describes the effectiveness of social trust information when designating a device for data transmission in a multi-hop device-o-device communication system. The focus of this use case is to achieve reliable transmission to transfer social data using device-to-device communication using the ITU's Trust Provisioning Framework building blocks. A trust index is determined by trust information using collected social data from the user's intermediate devices (e.g., a smartphone). Then trust index will be used to evaluate whether the user device is authorized to transmit the information.

Three main elements are involved in this use case: 1) User is an entity who owns devices (e.g., smartphone \& laptop) and exchange information with new

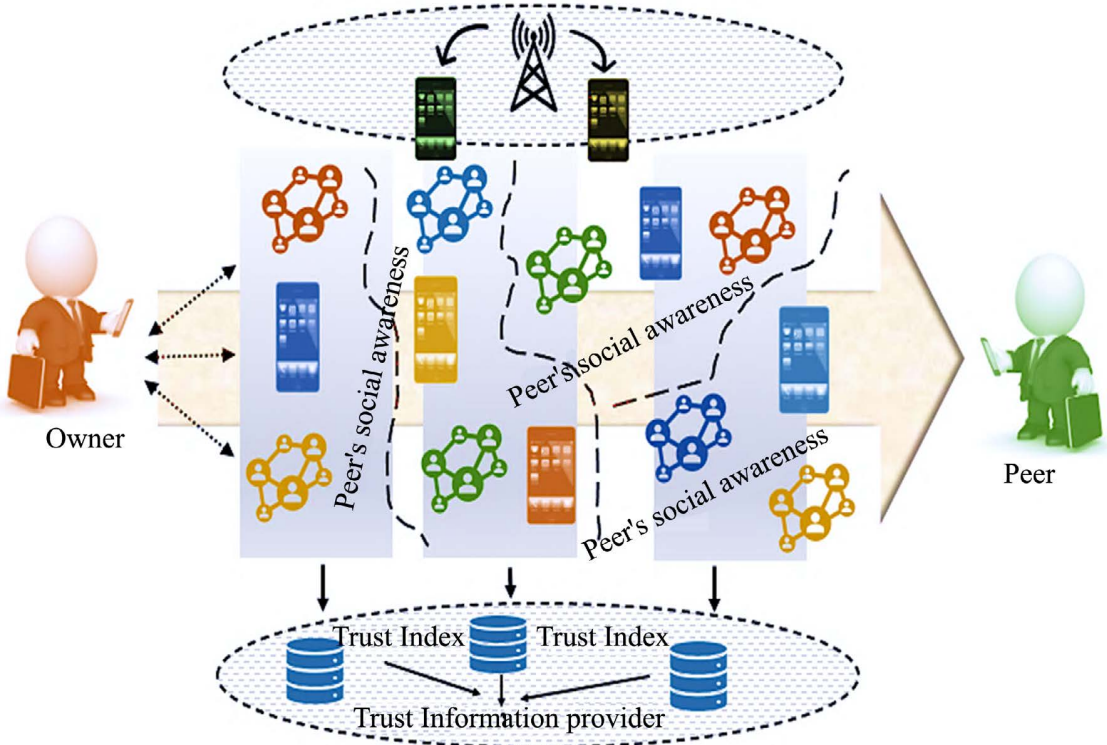

Figure 6. Use case of ITU trust provisioning framework for intermediate device selection. 
peers in the community, 2) Smartphone device is an intermediate entity to associate its owner's and peer's social awareness to other devices, and 3) Trust information provider (TIP) collects social data and utilized it to calculate a trust index. The workflow of this use case comprises the following stages: 1) A user requests to exchange information with other peers in a multi-hop device-to-device environment, 2) The user's smartphone requests the request the social information of other devices and peer's devices within the same community, and 3) TIP collects, calculates and notifies relevant information from other devices in the same environment. Based on this generic conceptual model, it shows the components of a trust provisioning framework that can be implemented in an ICT ecosystem with predictability, availability, and reliability of the information, and interoperability properties. The use case shows that the user is able to choose predictability properties to exchange the information. Once this process is completed based on user social trust and their trusted information provider, it collects data from other devices and can select the path to start trusted communication. Through the interoperability property, the user authorizes to send information and selects the transmission path to exchange the information.

\section{Good practices using ITU's Trust Provisioning Framework for Achieving UN SDGs}

ITU's trust provisioning framework contributes to SDGs emphasizing SDGs 9-Infrastructure, industrialization, and innovation. The SDGs 9 goal in particular target 9.c is to support building trusted and resilient CPS infrastructure and promoting sustainable industrialization and fostering innovation. Five years into the implementation of the 2030 Agenda and the Sustainable Development Goals (SDGs), many administrations, UN bodies, international and local agencies, and investors are developing or have initiated evidence-based inventory of progress. Almost 700 submissions were received, from 96 countries and 91 national governments including public and private sector, local authorities, academia, and others. According to the SDGs data visualization dashboard, currently, there are totally 513 SGDs good practices of which 116 are for SDGs 9. These figures [12] are being updated daily. Figure 7 shows SDG Good Practices by sector and by SDG respectively.

The Indigenous Navigator tool is a successful use case [13] from the UN's good practices. This use case shows the effectiveness of the trust provisioning framework using trusted CPS infrastructure and its services for the Indigenous Navigator tool. The Indigenous Navigator tool is a monitoring framework that facilitates indigenous communities to provide community-generated data and a set of tools for and by indigenous peoples to systematically observe the level of recognition and implementation of their rights. The navigator tools provide the indigenous communities abilities to evaluate their communities by a set of goals specified in the 2030 Agenda for Sustainable Development. The tools are set to provide various data collection methods considering that the used methods are 


\section{SDG Good Practices}

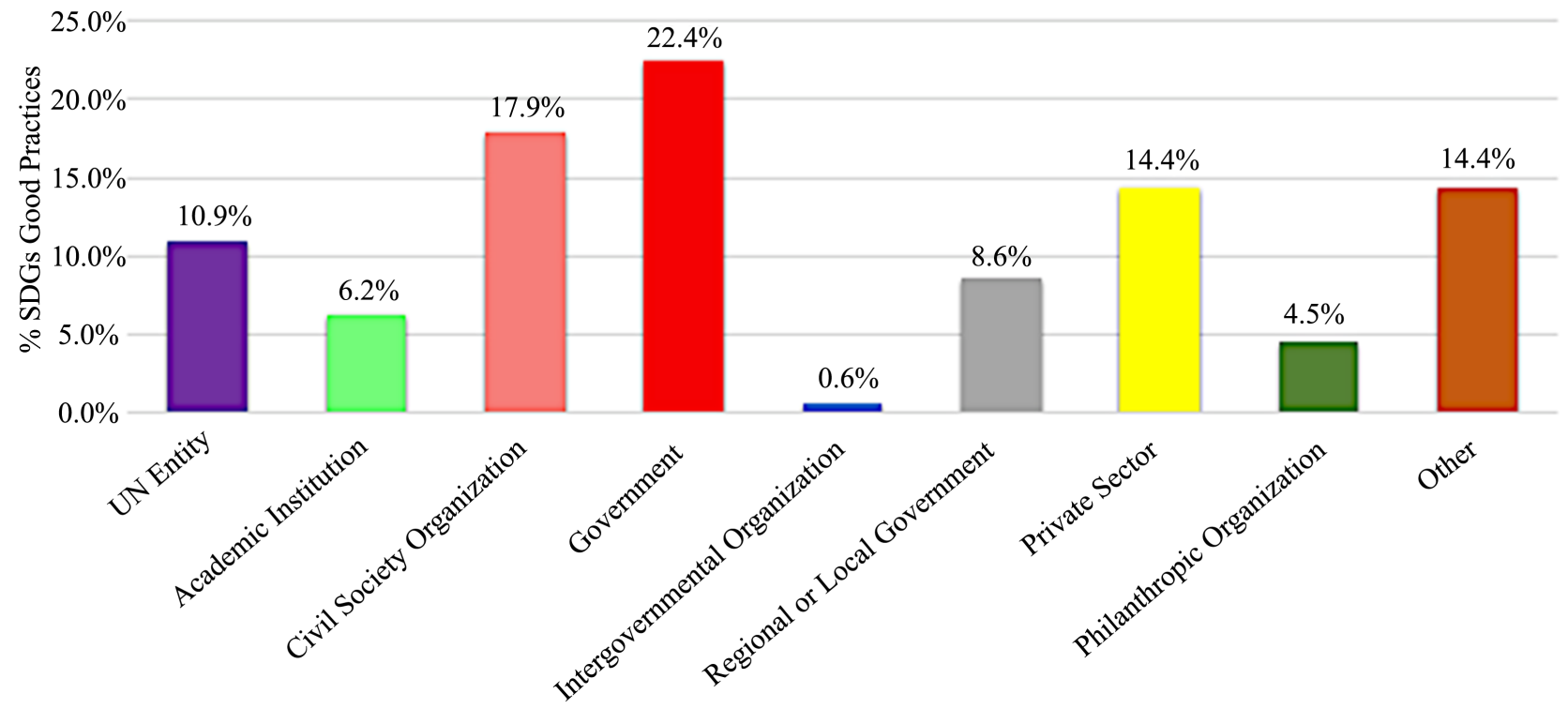

Figure 7. SDG good practices by sector.

all respectful of the communities' internal processes. The data collection results reflect valuable insights into the living conditions of indigenous peoples in the communities covered by the initiative. The indigenous navigator consists of a data portal and data collection tools, training, and capacity building throughout community workshops for regional indigenous partners, trusted local infrastructure supporting data collection, design and preparation of knowledge products such as a report, briefs, and fact sheets with the involvement and contributions of the communities. This use case shows that trust provisioning plays a vital role to assist the indigenous navigator and is an integral structure to provide a significant value of minimizing the risks and provisioning trust progress to achieve SDG 9. As shown in Figure 8, the indigenous navigator uses ITU's trust provisioning framework as a core platform in collaboration development of innovative policies, action standards, and technologies to effectively project into country-level, regional and global advocacy and policy dialogues allowing indigenous peoples to engage in connecting growth, inclusiveness, sustainability, innovation, and partnership both governmental, inter-governmental, and non-governmental. Since the COVID-19 pandemic, the communities using indigenous navigator tool [14] highlight the differentiated impact that the pandemic is having on their data, which varies from community to community. There are ongoing analysis and recommendations to pandemic response and recovery measures that are essential to community-generated data. The navigator is responsible to gather current and immediate information on the challenges indigenous communities are facing during the COVID-19 pandemic, as well as evaluating how they are coping with the crisis. This timely information is crucial for generating and producing responses to the COVID-19 crisis that are inclusive and take into account indigenous peoples' voices, aiming to reach a "better normal". 


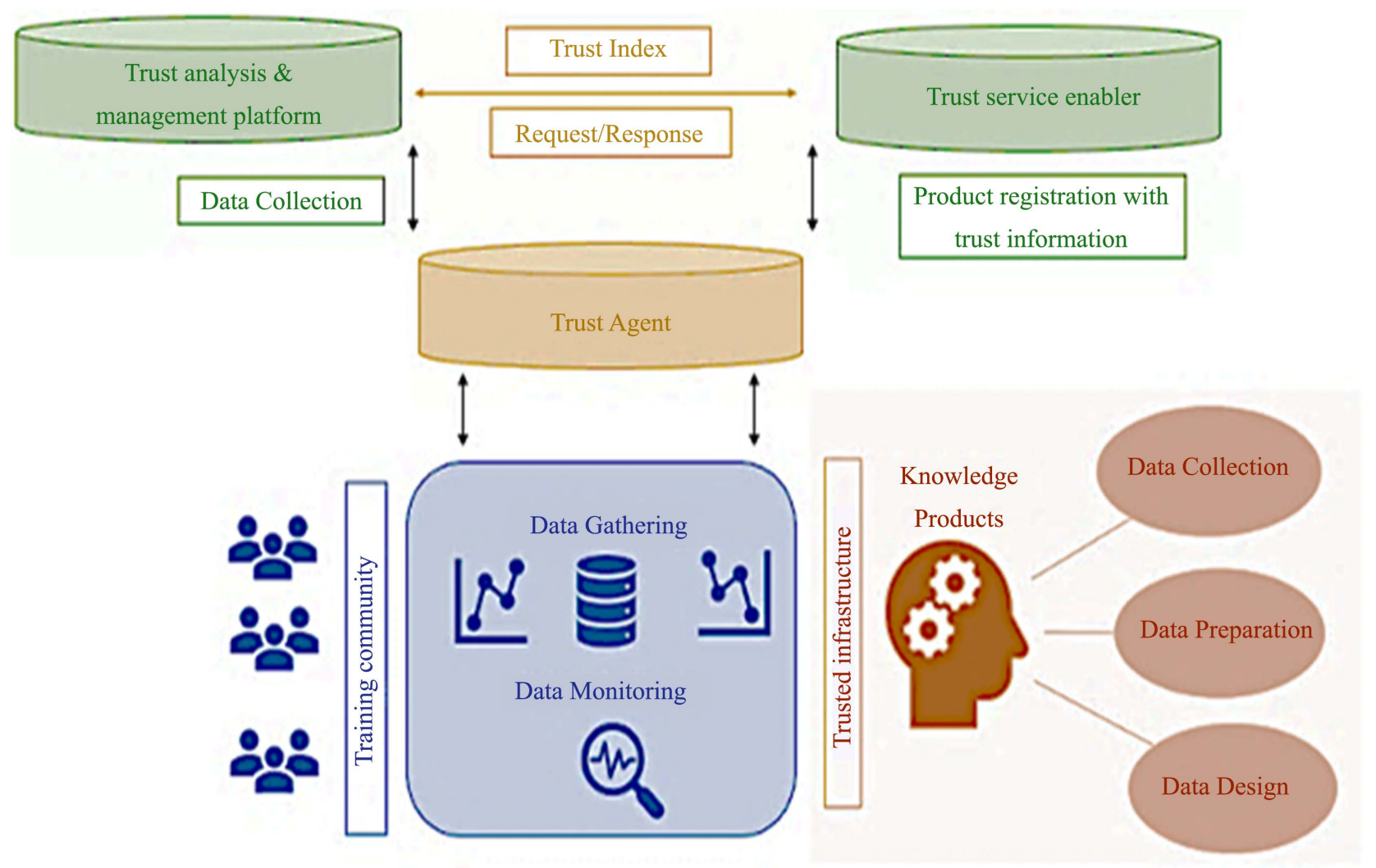

Figure 8. High-level indigenous navigator using ITU trust provision framework.

The indigenous navigator tool provides analyses and data set using data gathering and data monitoring across indigenous communities and organizations under trusted infrastructure. The tool provides two different sets of collected data: 1) Data explorer sets provide visualization of all submitted answers and comments and 2) Index explorer sets allow users to explore the analyzed index values and implementation status [15]. The indigenous navigator tool is an example of SDGs good practices and effectiveness of ITU's trust provision framework building blocks. It shows the components of a trust provisioning framework that can be implemented in an ICT ecosystem with predictability, availability, and reliability of the information, and interoperability properties. The navigator tool provides the user to choose predictability properties to exchange information within the trusted communities. Once this process is completed based on the user's trusted community and their trusted information provider, it collects data from other trust agents and can select the path to start trusted communication. Through the interoperability property, the user in the authorized community sends information and selects the transmission path to exchange the information.

\section{Conclusion}

While tackling the unpreceded challenges by the COVID-19 pandemic has become an urgent focus in many communities, this crisis has imposed an impact 
on the idea of the UN's sustainable development goals. The global responses of SDGs activities including the good practices, success stories, and lessons learned show, in particular, the communities' restriction impacted by pandemic have been increased, minimal or unaffected. According to SDG Good Practices the communities highly affected by pandemic are the offline population living in the least developed countries; only 19 percent use digital technologies and Internet connectivity, compared with 87 percent in developed countries. However, since the pandemic, many communities have committed to increasingly relying on the ICT infrastructure. While the ITU's trust provisioning contribution demonstrated to be an effective framework, it plays a vital role in allocating and coordinating the ongoing high demand for the use of trusted ICT infrastructure by the communities. This effort allows the urgency of ICTs infrastructure to provide a trusted platform and benefiting developing communities in building necessary physical infrastructure, strengthening cybersecurity and cyber privacy mechanism, developing digital skills for all community members, enhancing the regulatory and creating more resilient policies to increase access to trusted ICTs without any interruption.

\section{Conflicts of Interest}

The authors declare no conflicts of interest regarding the publication of this paper.

\section{References}

[1] Schwab, K. (2015) The Fourth Industrial Revolution-What It Means and How to Respond. Foreign Affair.

https://www.weforum.org/agenda/2016/01/the-fourth-industrial-revolution-what-it -means-and-how-to-respond/

[2] United Nations General Assembly (2014) (2014) Information and Communication Technology in the United Nations. Report of the Secretary-General, No. A/69/517. https://undocs.org/a/69/517

[3] Zhou, Y., Yu, F.R., Chen, J. and Kuo, Y. (2020) Cyber-Physical-Social Systems: A State-of-the-Art Survey, Challenges and Opportunities. IEEE Communications Surveys \& Tutorials, 22, 389-425. https://doi.org/10.1109/COMST.2019.2959013

[4] Cisco's Annual Internet Report (2020) Projecting the Future of Digital Transformation 2018-2023.

https://www.cisco.com/c/en/us/solutions/executive-perspectives/annual-internet-re port/infographic-c82-741491.html

[5] Candra, Z.C.M., Truong, H. and Dustdar, S. (2016) On Monitoring Cyber-Physical-Social Systems. 2016 IEEE World Congress on Services (SERVICES), San Francisco, 27 June-2 July 2016, 56-63. https://doi.org/10.1109/SERVICES.2016.14

[6] Um, T., Lee, G.M. and Choi, J.K. (2016) Strengthening Trust in the Future Social-Cyber-Physical Infrastructure: An ITU-T Perspective. IEEE Communications Magazine, 54, 36-42. https://doi.org/10.1109/MCOM.2016.7565270

[7] International Telecommunication Union (ITU) (2017) Trust in ICT Report 2017. International Telecommunication Union, Geneva. 
https://www.itu.int/dms pub/itu-t/opb/tut/T-TUT-TRUST-2017-PDF-E.pdf

[8] International Telecommunication Union (ITU) (2017) The Basic Principles of Trusted Environment in Information and Communication Technology Infrastructure. Recommendation No. Y.3051. https://www.itu.int/rec/T-REC-Y.3051

[9] International Telecommunication Union (ITU) (2017) Overview of Trust Provisioning in Information and Communication Technology Infrastructures and Services. Recommendation No. Y.3052.

https://www.itu.int/rec/T-REC-Y.3052-201703-I/en

[10] Sheth, A., Anantharam, P. and Henson, C. (2013) Physical-Cyber-Social Computing: An Early 21st Century Approach. IEEE Intelligent Systems, 28, 78-82.

https://doi.org/10.1109/MIS.2013.20

[11] International Telecommunication Union (ITU) (2016) Trust Provisioning for Future ICT Infrastructures and Services.

https://www.itu.int/en/publications/Pages/publications.aspx?lang=en\&media=electr onic\&parent=T-TUT-TRUST-2016-1

[12] SGDs Good Practices Data Virtualization Dashboard (2020). https://dsdg.maps.arcgis.com/apps/opsdashboard/index.html\#/fe3ce6a527e04f329af $\underline{155 \mathrm{fbf} 1331 \mathrm{a} 02}$

[13] United Nations (2017) Generating Disaggregated Indigenous Community-Data through the Indigenous Navigator Initiative to Achieve the SDGs (\#SDGAction29578).

https://sustainabledevelopment.un.org/partnership/?p=29578

[14] International Work Group for Indigenous Affairs (2020) The Impact of COVID-19 on Indigenous Communities: Insights from the Indigenous Navigator. https://www.iwgia.org/en/resources/publications/3878-ini-covid-19-report.html

[15] Indigenous Navigator (2020) Indigenous Navigator Survey, Data and Index Modules.

https://indigenousnavigator.org/indigenous-data/beta-launch-new-indigenous-navi gator-tool 